\title{
Article \\ Both Allene Oxide Synthases Genes Are Involved in the Biosynthesis of Herbivore-Induced Jasmonic Acid and Herbivore Resistance in Rice
}

\author{
Jiamei Zeng ${ }^{1,+} \mathbb{D}$, Tongfang Zhang ${ }^{1,2,+}$, Jiayi Huangfu ${ }^{1}, \operatorname{Ran~Li}^{1}$ and Yonggen Lou ${ }^{1, *(\mathbb{D})}$ \\ 1 State Key Laboratory of Rice Biology \& Ministry of Agriculture Key Lab of Molecular Biology of Crop \\ Pathogens and Insects, Institute of Insect Sciences, Zhejiang University, Hangzhou 310058, China; \\ tsengchiamei@zju.edu.cn (J.Z.); zhangtf@swu.edu.cn (T.Z.); luckyfjy@163.com (J.H.); rli05@zju.edu.cn (R.L.) \\ 2 College of Food Science, Southwest University, Chongqing 400715, China \\ * Correspondence: yglou@zju.edu.cn; Tel.: +86-571-8898-2622 \\ + These authors contributed equally to this work.
}

Citation: Zeng, J.; Zhang, T.; Huangfu, J.; Li, R.; Lou, Y. Both Allene Oxide Synthases Genes Are Involved in the Biosynthesis of Herbivore-Induced Jasmonic Acid and Herbivore Resistance in Rice. Plants 2021, 10, 442. https://doi.org/ $10.3390 /$ plants10030442

Academic Editor: Thierry Heitz

Received: 25 January 2021

Accepted: 22 February 2021

Published: 26 February 2021

Publisher's Note: MDPI stays neutral with regard to jurisdictional claims in published maps and institutional affiliations.

Copyright: (c) 2021 by the authors. Licensee MDPI, Basel, Switzerland. This article is an open access article distributed under the terms and conditions of the Creative Commons Attribution (CC BY) license (https:// creativecommons.org/licenses/by/ $4.0 /)$.

\begin{abstract}
Allene oxide synthase (AOS) is the second enzyme in the biosynthesis of the plant defensive hormone jasmonic acid (JA). In rice, there are two AOSs, OsAOS1 and OsAOS2. However, the role of these two AOS genes in herbivore-induced defenses in rice remains unidentified. We cloned the two rice AOS genes and observed that the transcript level of both OsAOS1 and OsAOS2 was enhanced by mechanical wounding, the infestation of the striped stem borer (SSB) (Chilo suppressalis) or brown planthopper (BPH) (Niaparvata lugens), and treatment with JA; however, OsAOS1 responded more rapidly to SSB infestation and JA treatment than did OsAOS2. The antisense expression of OsAOS1 (as-aos1) or OsAOS2 (as-aos2) decreased levels of SSB- or BPH-induced JA, which, in turn, reduced the production of SSB-induced trypsin protease inhibitor (TrypPI) and volatiles as well as the resistance of rice to SSB. In contrast, BPH preferred to feed and oviposit on wild-type (WT) plants over as-aos1 and as-aos2 plants. Moreover, the survival of BPH nymphs on as-aos1 or as-aos2 lines was significantly lower than on WT plants. The increased resistance of as-aos1 or as-aos 2 plants to BPH correlated with higher levels of $\mathrm{BPH}$-induced $\mathrm{H}_{2} \mathrm{O}_{2}$ and SA. These results indicate that OsAOS1 and OsAOS2 are both involved in herbivore-induced JA biosynthesis and play a vital role in determining the resistance of rice to chewing and phloem-feeding herbivores.
\end{abstract}

Keywords: allene oxide synthase; jasmonic acid; rice; herbivore resistance; salicylic acid; hydrogen peroxide

\section{Introduction}

When infested by herbivorous insects, plants recognize herbivore-associated molecular patterns and then initiate defense-related signaling pathways; these activated pathways, thus, induce the expression of defensive genes and the biosynthesis of defensive compounds, which, in turn, enhance the resistance of plants to herbivorous insects $[1,2]$. In these signaling pathways, the jasmonates-mediated pathway plays a central role [3-5]. The biosynthesis of jasmonates starts with the transformation from $\alpha$-linolenic acid ( $\alpha$-LeA) (18:3) released from chloroplast membranes and continues to 13S-hydroperoxy$(9 Z, 11 E, 15 Z)$-octadecatrienoic acid (13-HPOT) catalyzed by 13-lipoxygenase (LOX). Subsequently, the 13-HPOT is oxidized by an allene oxide synthase (AOS) to form an unstable epoxide, which is cyclized to the 12-oxo phytodienoic acid (12-OPDA) by an allene oxide cyclase (AOC). Finally, OPDA is reduced/converted to jasmonic acid (JA) by OPDA reductase 3 (OPR3) and three cycles of $\beta$-oxidation in the peroxisomes [6,7]. JA may then form distinct jasmonates via different metabolic conversions. Therefore, it is clear that the enzyme AOS is a regulatory point in the biosynthesis of jasmonates [8,9], which play vital roles in plant development and responses to abiotic and biotic stresses [10]. 
Thus far, many AOS genes have been cloned and characterized in various dicots and monocots [11,12]. The number of genes encoding AOS varies with plant species. For example, a single AOS gene has been described in Arabidopsis [13], two AOSs have been found in barley (Hordeum vulgare) [14] and tomato (Solanum lycopersicum) [15,16], and three AOSs have been identified in potato (S. tuberosum) [17]. Despite conflicting reports on the number of AOS genes in rice (one [18], two [19], four [20], or five [21]), a series of detailed database searches followed by functionality tests has convincingly shown that there are only two AOS genes whose encoding proteins localize in the chloroplast [11].

Rice, one of the most important staple food crops in the world, suffers heavily from insect pests [22], among which striped stem borer (SSB) Chilo suppressalis (Lepidoptera: Pyralidae), a chewing herbivore, and brown planthopper (BPH) Nilaparvata lugens (Stål) (Hemiptera: Delphacidae), a piercing-sucking feeder, are two of the most important [23]. It has been well documented in rice that herbivorous insect infestation activates a variety of defensive signaling pathways mediated mainly by JA, salicylic acid (SA), ethylene, and $\mathrm{H}_{2} \mathrm{O}_{2}$; these signaling pathways facilitate the accumulation of trypsin proteinase inhibitors (TrypPIs) and the release of herbivore-induced plant volatiles (HIPVs), thereby enhancing the direct and indirect resistance of rice to herbivores [24,25]. The expression levels of both OsAOS1 and OsAOS2 are significantly induced following the infection of rice blast fungus (Magnaporthe grisea) (Magnaporthales: Magnaporthaceae) $[18,26]$. Overexpression of OsAOS2 enhances the activation of pathogenesis-related (PR) genes and increases the resistance of rice to M. grisea [26]. However, the role of OsAOSs in herbivore-induced defense responses in rice remains largely unknown.

In this study, we cloned the two rice AOSs and characterized their roles in herbivoreinduced defenses in rice. We found that the expression of OsAOS1 and OsAOS2 was induced by mechanical wounding, herbivore infestation, and JA treatment. Both OsAOS1 and OsAOS2 positively regulate the production of herbivore-induced JA, volatiles, and TrypPIs but negatively modulate the biosynthesis of herbivore-induced $\mathrm{SA}$ and $\mathrm{H}_{2} \mathrm{O}_{2}$. Moreover, silencing OsAOS1 or OsAOS2 reduced the resistance of rice to the chewing herbivore SSB but enhanced the resistance to the piercing-sucking herbivore $\mathrm{BPH}$. These findings demonstrate that both OsAOS1 and OsAOS2 play an important role in the biosynthesis of herbivore-induced JA and in the resistance of rice to herbivores.

\section{Results}

2.1. Both OsAOS1 and OsAOS2 Were Induced by Mechanical Wounding, Herbivore Infestation, and JA but Have Different Patterns

We cloned the full-length cDNA of the sequenced rice AOS genes, OsAOS1 (TIGR ID Os03g55800) and OsAOS2 (Os03g12500), using reverse transcription polymerase chain reaction (RT-PCR) (Figure S1). The first AOS gene has an open reading frame (ORF) of $1,539 \mathrm{bp}$ and encodes 513 amino acids; its predicted molecular mass is $56.50 \mathrm{kDa}$ and its $\mathrm{pI}$ is 9.52. The second AOS gene has an ORF of 1,437 bp and encodes 479 amino acids; its predicted molecular mass is $52.27 \mathrm{kDa}$ and its $\mathrm{pI}$ is 8.26 . Sequence alignments revealed that both OsAOS1 and OsAOS2 shared $65.75 \%$ and $53.70 \%$ identity, respectively, in nucleotide sequence and amino acid sequence (Figure S2).

Quantitative real-time (qRT)-PCR analysis revealed that constitutive transcript levels of both OsAOS1 and OsAOS2 in rice leaf sheaths were low. When plants were mechanically wounded, infested with herbivores, or treated with JA, transcript levels of the two AOS genes increased with different patterns (Figure 1a-f): generally, OsAOS1 responded to these treatments more strongly than did OsAOS2; moreover, SSB infestation and JA treatment induced the expression of OsAOS2 slowly ( $\geq 4 \mathrm{~h}$ after treatment) but induced OsAOS1 quickly. BPH infestation also elicited the accumulation of OsAOS1 and OsAOS2 transcripts but slowly and weakly (Figure 1g,h). SA treatment did not induce the expression of either OsAOS1 or OsAOS2 (Figure S3). These data suggest that although OsAOS1 and OsAOS2 exhibited different induced expression profiles, both seem to be involved in the herbivore-induced JA signaling pathway in rice. 


\section{OsAOS1}

(a)

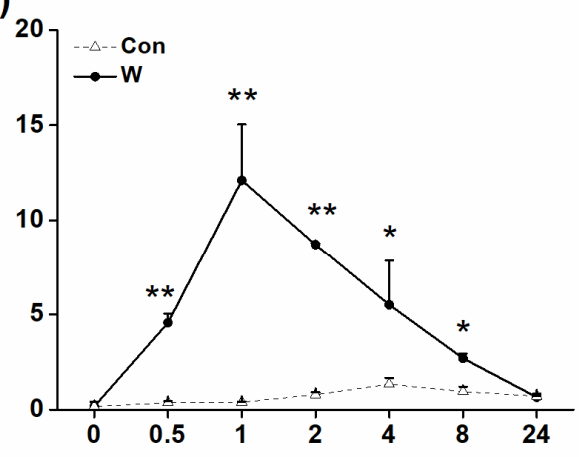

(c)

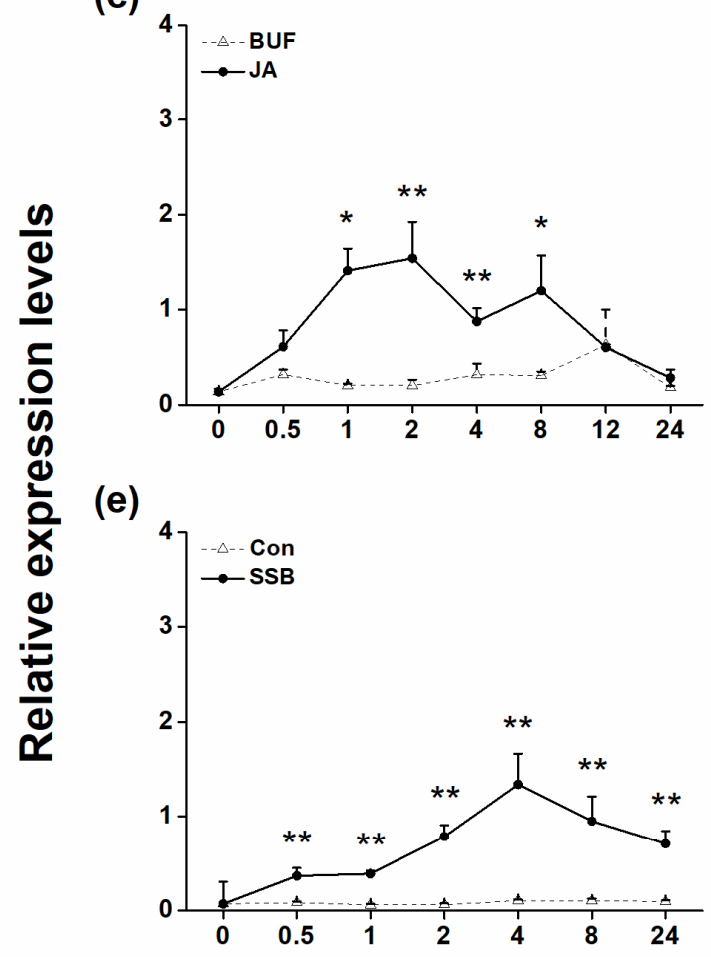

(g)

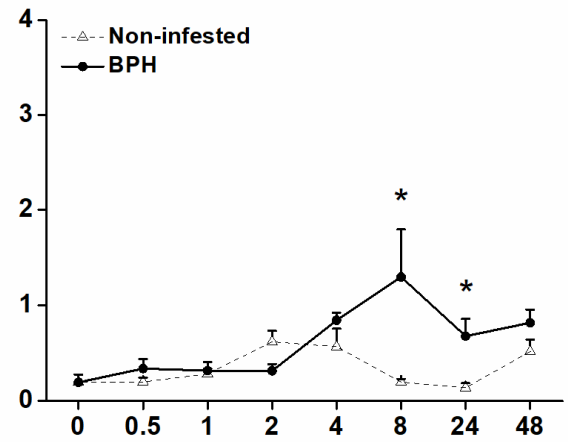

(b)

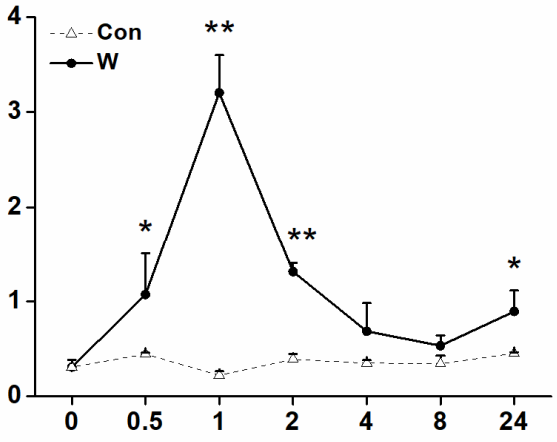

(d)

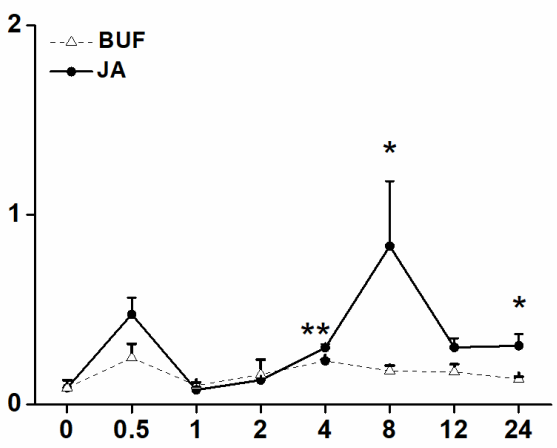

(f)

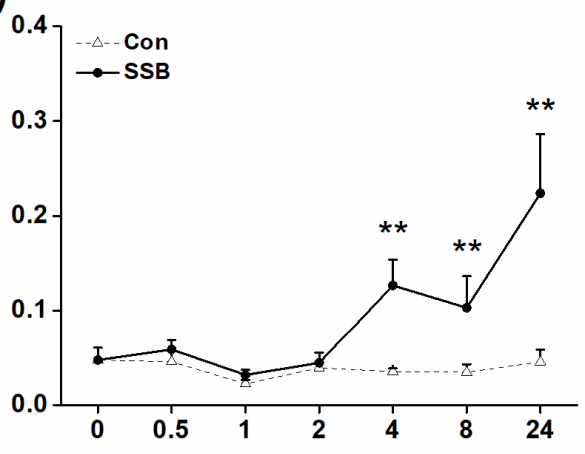

(h)

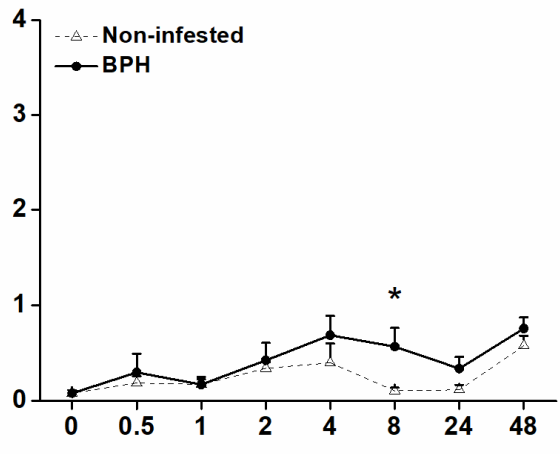

Time after eliciation (h)

Figure 1. Transcript levels of OsAOS1 and OsAOS2 in rice after various treatments. Mean expression levels (relative to expression levels of OsACT, $+\mathrm{SE}, n=5)$ of OsAOS1 (a,c,e,g) and OsAOS2 (b, d,f,h) in rice leaf sheaths that were treated by mechanically wounded $(\mathrm{W}, \mathbf{a}, \mathbf{b})$, jasmonic acid (JA, c,d), or infested by rice striped stem borer (SSB, e,f) or brown planthopper (BPH, $\mathbf{g}, \mathbf{h})$. BUF, sodium phosphate buffer; Non-infested, plants with an empty cylinder; Con, control plants. Asterisks indicate significant differences between treatments and controls ${ }^{*} p<0.05,{ }^{* *} p<0.01$, Student's $t$-test). 


\subsection{Silencing OsAOS1 and OsAOS2}

We constructed a pCAMBIA-1301 transformation vector carrying reverse fragments of OsAOS (Figure S4) and created transgenic rice plants using Agrobacterium tumefaciensmediated transformation. By $\beta$-glucuronidase (GUS) staining and hygromycin resistance selection, we obtained six $\mathrm{T}_{2}$ homozygous lines, including three OsAOS1-silenced lines (as-aos1 lines: as1-3, as1-5, and as1-10) and three OsAOS2-silenced lines (as-aos2 lines: as2-10, as2-20, and as2-58) (Figure S5). Transcriptional analysis showed that SSB-induced transcript levels of OsAOS1 and OsAOS2 in as-aos1 lines (as1-3, as1-5, and as1-10) and as-aos 2 lines (as2-10, as2-20, and as2-58) were only $38.02 \%, 16.61 \%$, and $38.34 \%$, and $36.18 \%$, $24.91 \%$, and $27.11 \%$ of those in wild-type (WT) plants $1 \mathrm{~h}$ after SSB infestation, respectively (Figure S6). In rice, the gene whose nucleotide sequence has the highest similarity to OsAOS1 is OsAOS2 (65.75\%, Figure S2) and vice versa. Transcription analysis revealed that both OsAOS1 and OsAOS2 antisense constructs silenced the transcript accumulation of the targeted gene but not the other (Figure S7), suggesting that the specificity of the RNAi sequence for OsAOS1 or OsAOS2 is high. No obvious difference in growth phenotype was observed between WT plants and transgenic lines during their entire development (Figure S8).

\subsection{Both OsAOS1 and OsAOS2 Mediate Herbivore-Induced JA and SA Biosynthesis}

JA and SA play an important role in herbivore-induced defense responses in rice [25]. Hence, we asked if silencing OsAOS1 or OsAOS2 influences the production of the basal and herbivore-induced JA and SA in rice. Phytohormone analysis revealed that basal and SSB-induced levels of JA in both as-aos1 and as-aos2 lines were lower than those in WT plants, although the difference in basal and induced (1.5 h after SSB infestation) levels of JA between WT plants and as-aos2 lines was not significant (Figure 2a,b). Similarly, silencing OsAOS1 or OsAOS2 also decreased BPH-induced levels of JA in plants $8 \mathrm{~h}$ and $48 \mathrm{~h}$ after $\mathrm{BPH}$ infestation (Figure 2c). In contrast, no difference was found in constitutive SA levels between WT plants and transgenic lines; however, $3 \mathrm{~h}$ after SSB infestation or $8 \mathrm{~h}$ after BPH infestation, SA levels in as-aos1 and as-aos 2 lines were significantly higher than those in WT plants (Figure 2d-f).

\subsection{OsAOS1 and OsAOS2 Positively Regulates TrypPI Activity, Volatile Emmission, and Rice Resistance to SSB}

TrypPIs are important direct defensive compounds against SSB in rice [25]. To investigate the role of OsAOS1 and OsAOS2 in regulating the activity of TrypPIs, we measured TrypPI activity in WT plants and transgenic lines 3 days after SSB infestation. Compared with WT plants, both as-aos1 and as-aos2 lines showed less SSB-induced activity in TrypPIs (Figure 3a).

It has been reported that SSB caterpillar infestation induces the production of rice volatiles that attract the natural enemies of SSB caterpillars [27]. Thus, we collected and analyzed the volatiles released from WT and transgenic plants that were infested by SSB or not. The results showed that constitutive levels of volatiles emitted from WT, as-aos1 and, as-aos 2 plants were similar (Figure 3b). However, when plants were infested by SSB, the total amount of volatiles released from as-aos 1 and as-aos 2 plants was lower than that emitted from WT plants, although the production of volatiles from all these plants were induced by SSB infestation (Figure 3b,c; Table S1). Moreover, levels of four compounds, 2 -heptanol, $\alpha$-copaene, $\mathrm{n}$-tetradecane, and (E)- $\beta$-caryophyllene were significantly lower in as-aos1 and as-aos2 plants than in WT plants (Figure 3c).

SSB caterpillars gained more mass on as-aos1 and as-aos2 lines than on WT plants (Figure 4a). Consistent with this finding, as-aos1 and as-aos2 plants were damaged more severely by SSB than were WT plants (Figure $4 \mathrm{~b}$ ). To determine whether the reduction in JA level in as-aos1 and as-aos2 lines was sufficient to explain the reduction in TrypPI activity and SSB resistance in rice, we measured TrypPI activity in, and SSB caterpillar mass on, as-aos1 and as-aos 2 lines complemented with JA. We observed that when plants 
were treated with JA, SSB-induced TrypPI levels in as-aos1 and as-aos2 lines were similar to those in WT plants (Figure 4c); moreover, SSB caterpillars fed on JA-treated as-aos1 and as-aos 2 lines gained the same weight as those fed on JA-treated WT plants (Figure 4d).
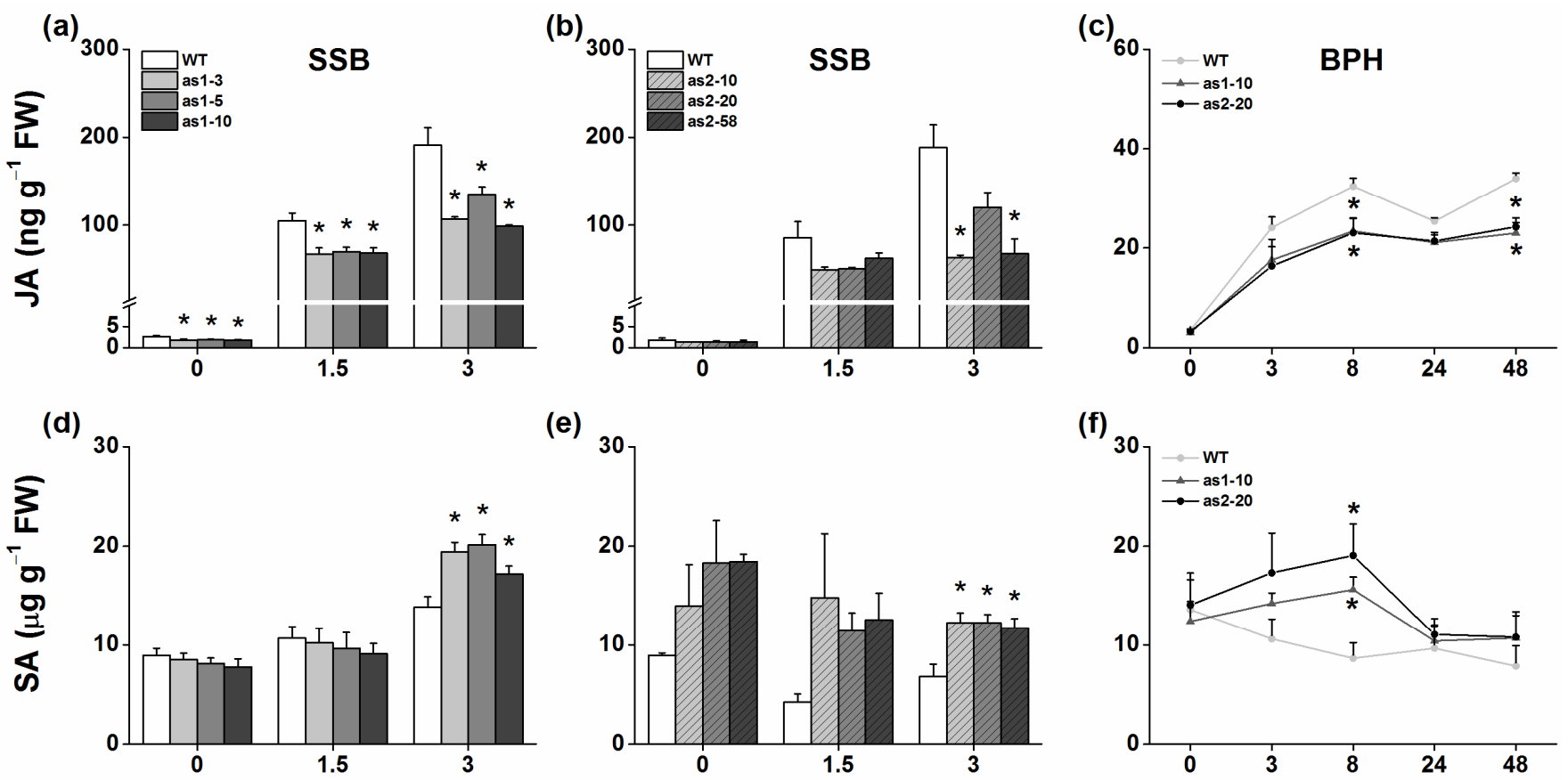

(e)

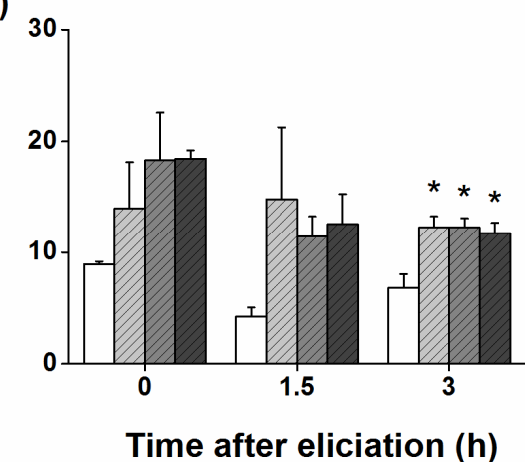

(f)

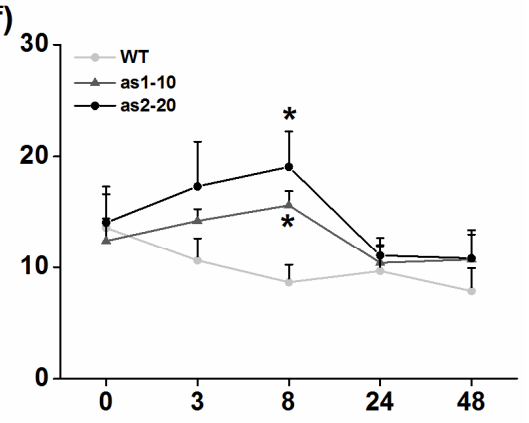

Figure 2. Levels of JA and SA in as-aos lines and WT plants that were infested by SSB or BPH. Mean levels $(+\mathrm{SE}, n=5)$ of JA (a-c) and SA (d-f) levels in leaf sheaths of as-aos1 (as1-3, as1-5, and as1-10), as-aos2 (as2-10, as2-20, and as2-58) and WT plants that were individually infested by a third-instar SSB larva or 15 gravid BPH females. FW, fresh weight. Asterisks indicate significant differences between as-aos lines and WT plants at the indicated times $\left({ }^{*} p<0.05\right.$, Tukey's honest significant difference (HSD) post-hoc test).

\subsection{OsAOS1 and OsAOS2 Negatively Modulate $\mathrm{H}_{2} \mathrm{O}_{2}$ Accumulation and Rice Resistance to $\mathrm{BPH}$}

We also tested whether silencing OsAOS1 or OsAOS2 influences the resistance of rice to $\mathrm{BPH}$. When as-aos1 or as-aos2 lines and WT plants were exposed to a $\mathrm{BPH}$ colony, gravid BPH females preferred to feed and lay eggs on WT plants (Figure 5a,b, and insets). Moreover, the survival of BPH nymphs fed on as-aos1 or as-aos2 lines was lower than the survival of those fed on WT plants (Figure $5 \mathrm{c}, \mathrm{d}$ ).

$\mathrm{H}_{2} \mathrm{O}_{2}$ signaling positively modulates the resistance of rice to $\mathrm{BPH}[25,28,29]$. Hence, we measured $\mathrm{H}_{2} \mathrm{O}_{2}$ levels in WT, as-aos1, and as-aos 2 plants when they were infested by gravid $\mathrm{BPH}$ females. The results revealed that levels of $\mathrm{BPH}$-induced $\mathrm{H}_{2} \mathrm{O}_{2}$ were significantly higher in as-aos1 and as-aos2 lines than in WT plants (Figure 5e). 

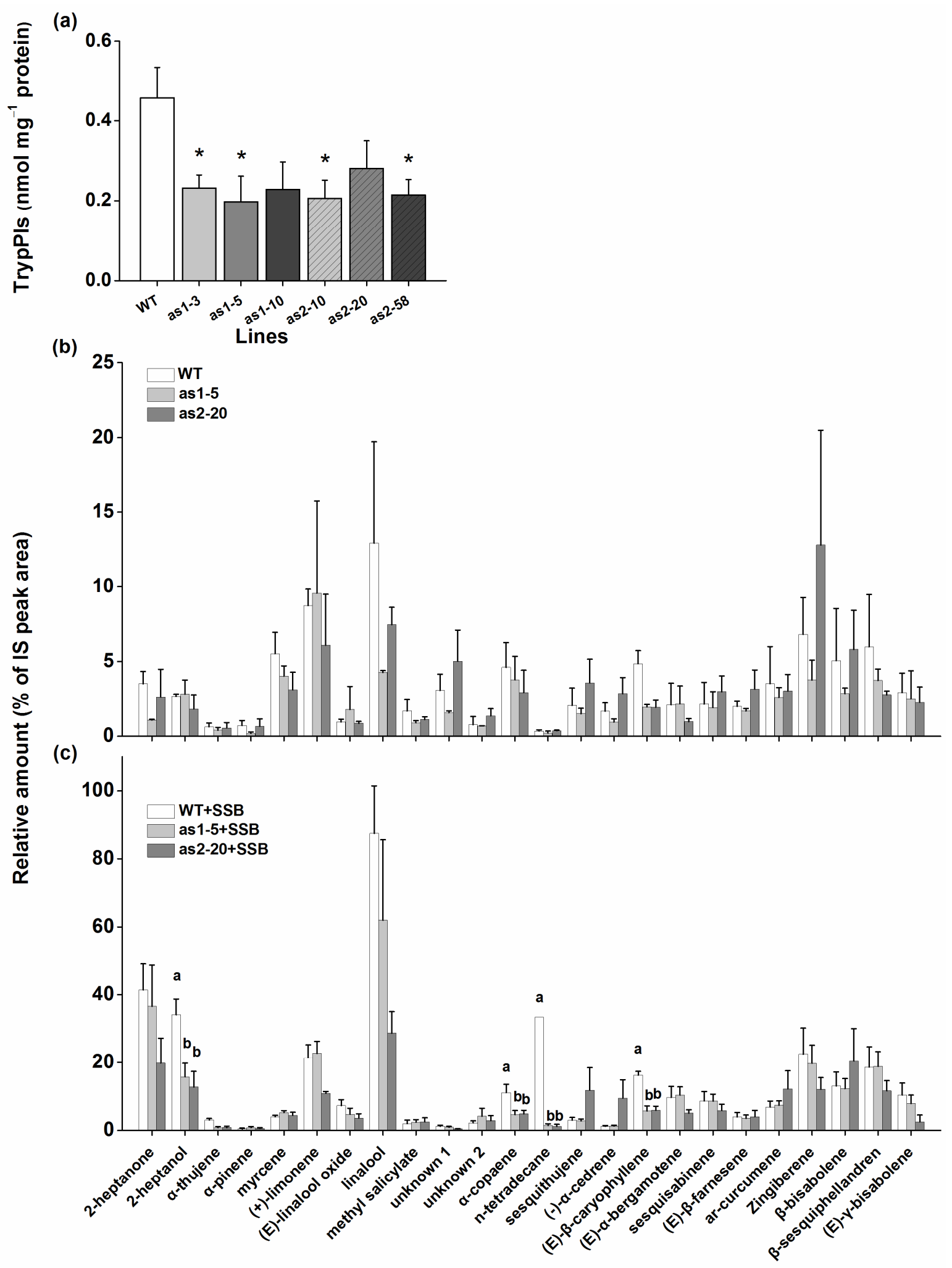

Chemical

Figure 3. OsAOS1 and OsAOS2 regulate SSB-induced TrypPI activity and volatile emission. (a) Mean TrypPI activity $(+\mathrm{SE}, n=5)$ in as-aos1, as-aos2, and WT plants that were individually infested by a third-instar SSB larva for 3 days. Mean amounts (\% of IS peak area, $+\mathrm{SE}, n=5$ ) of volatiles emitted from as-aos1 (as1-5), as-aos2 (as2-20), and WT plants that were not manipulated (b) or were individually infested with a third-instar SSB larva for $24 \mathrm{~h}$ (c). Asterisks and letters indicate significant differences in as-aos lines compared with WT plants $\left({ }^{*} p<0.05\right.$, Tukey's HSD post-hoc test). 
(a)

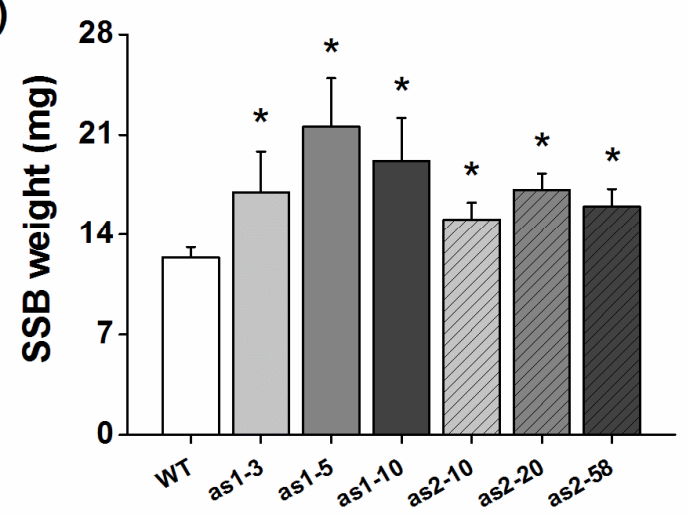

(b)

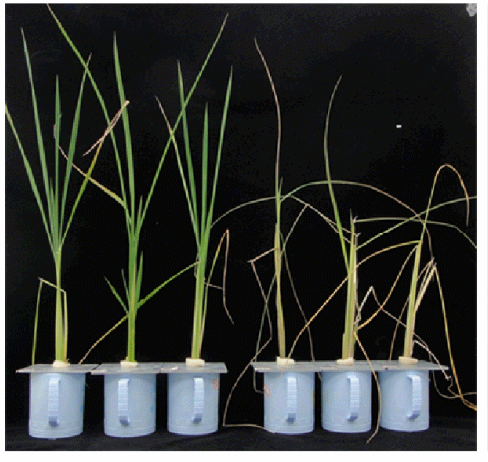

WT as-aos1

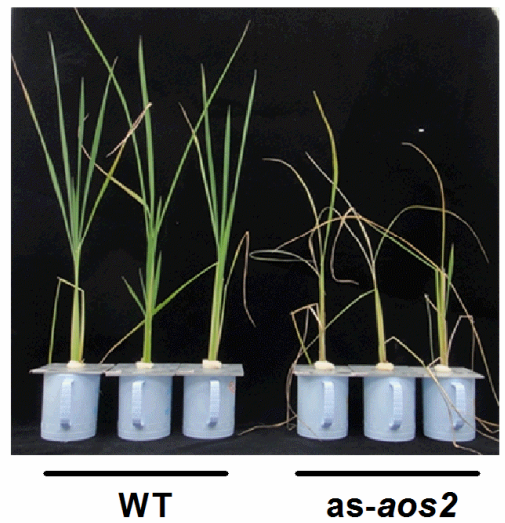

(c)

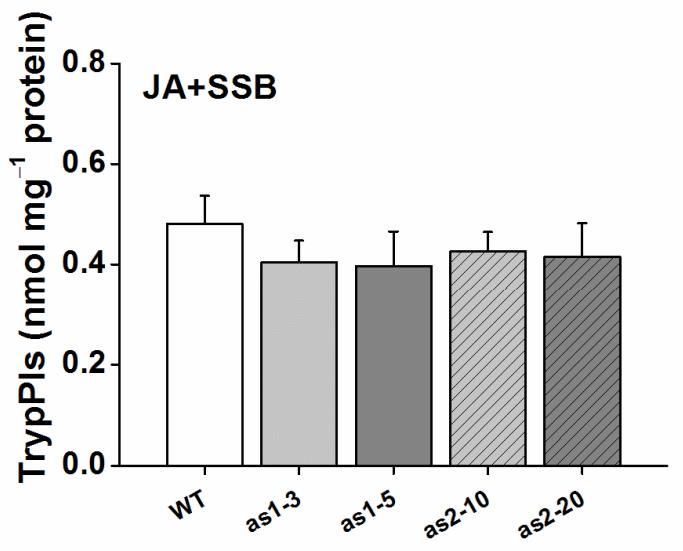

(d)

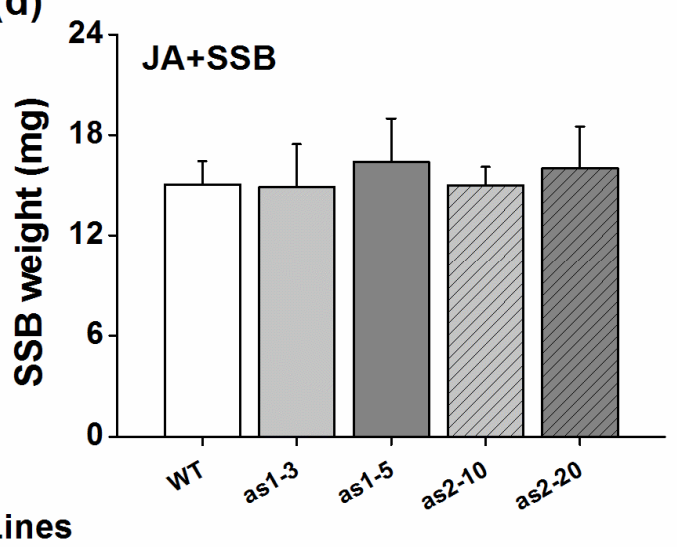

Figure 4. OsAOS1 and OsAOS2 positively regulate the direct resistance of rice to SSB. (a) Mean larval weight $(+\mathrm{SE}, n=30)$ of SSB fed on as-aos1 (as1-3, as1-5, and as1-10), as-aos2 (as2-10, as2-20, and as2-58), and WT plants for 12 days. (b) Damaged phenotypes of as-aos1, as-aos2, and WT plants that were individually infested by a third-instar SSB larva for 10 days. (c) Mean TrypPI activity (+SE, $n=5$ ) in as-aos1, as-aos2, and WT plants that were first individually sprayed with $2 \mathrm{~mL}$ of JA (100 $\left.\mu \mathrm{g} \mathrm{mL}^{-1}\right)$ in the sodium phosphate buffer for 1 day, followed by a third-instar SSB larvae infestation for 3 days. (d) Mean larval mass (+SE, $n=30$ ) of SSB 12 days after they fed on as-aos1, as-aos2, and WT plants that were individually treated with JA as stated above. Asterisks indicate significant differences in as-aos lines compared with WT plants ${ }^{*} p<0.05$, Tukey's HSD post-hoc test). 

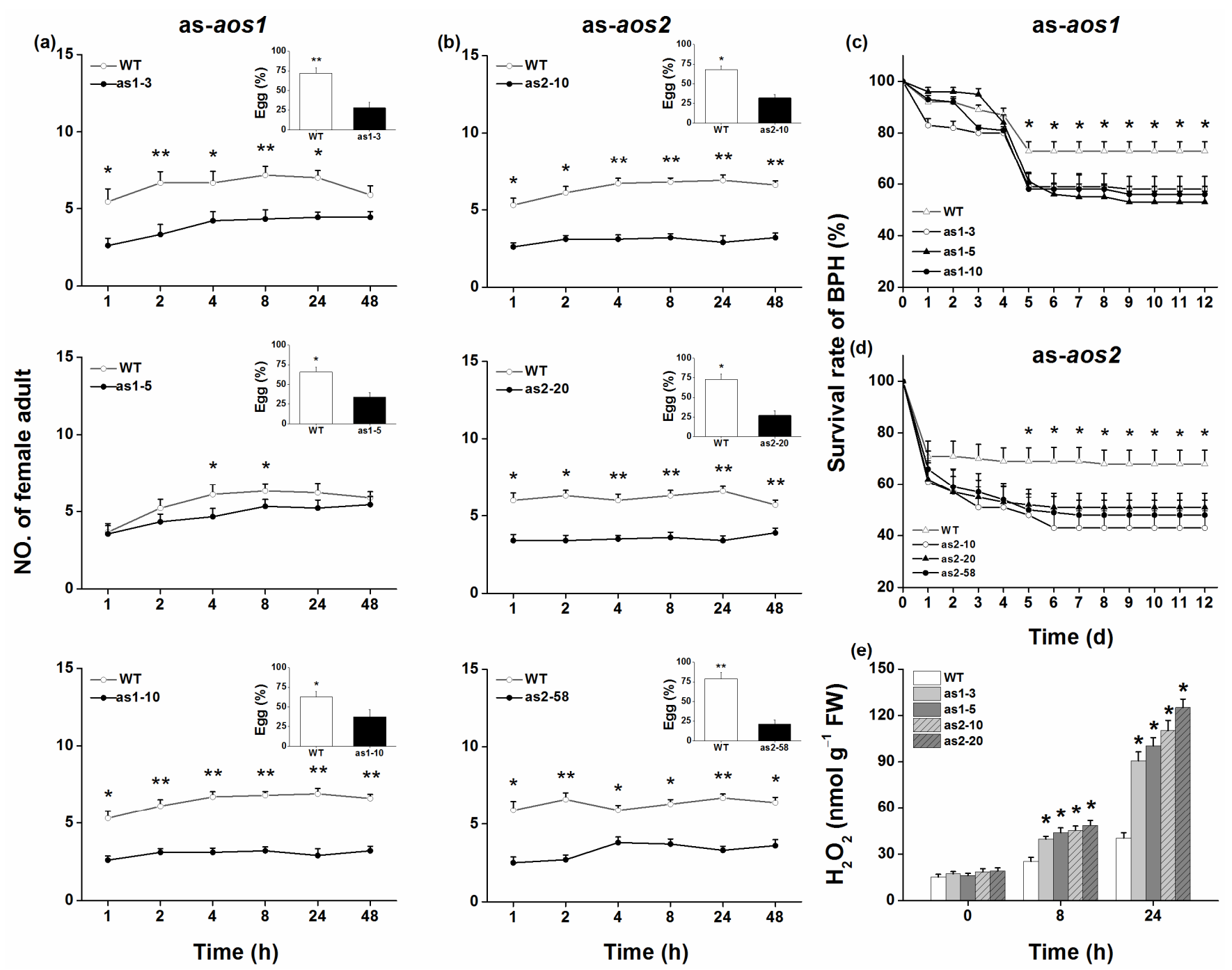

Figure 5. OsAOS1 and OsAOS2 negatively modulate the resistance of rice to BPH. (a,b) Mean number of gravid BPH females per plant (+SE, $n=10$ ) on pairs of plants (WT versus as-aos1 (as1-3, as1-5, and as1-10) (a) or as-aos2 (as2-10, as2-20, and as2-58) (b), respectively), 1-48 h after plant pairs were exposed to 13 insects. Inserts: Mean percentage $(+\mathrm{SE}, n=10)$ of BPH eggs per plant on pairs of plants as stated above. $(\mathbf{c}, \mathbf{d})$ Mean survival rates $(+\mathrm{SE}, n=10)$ of BPH newly hatched nymphs fed on as-aos1, as-aos2, and WT plants, 1-12 days after the nymphs were placed on plants. (e) Mean concentrations $(+\mathrm{SE}, n=5)$ of $\mathrm{H}_{2} \mathrm{O}_{2}$ in as-aos1, as-aos2, and WT plants that were individually infested by 12 gravid BPH females for 8 and $24 \mathrm{~h}$. Asterisks indicate significant differences in as-aos lines compared with WT plants $\left({ }^{*} p<0.05,{ }^{* *} p<0.01\right.$, Student's $t$-tests $(\mathbf{a}, \mathbf{b})$ or Tukey's HSD post-hoc test $(\mathbf{c}-\mathbf{e}))$.

\section{Discussion}

In this study, we evaluated the role of two OsAOS genes in the biosynthesis of herbivore-induced JA and the resistance of rice to herbivores. Several lines of evidence suggest that both OsAOS1 and OsAOS2 play an important role in these processes. First, both OsAOS1 and OsAOS2 were induced by SSB caterpillar infestation, gravid BPH female infestation, mechanical wounding, or JA treatment but not SA treatment (Figure 1 and Figure S2). Second, silencing OsAOS1 or OsAOS2 reduced levels of herbivore-induced JA and enhanced levels of SA (Figure 2), which in turn decreased the production of SSBinduced TrypPIs and volatiles (Figure 3), and the resistance of rice to SSB (Figure 4a,b). Third, supplementing with JA on as-aos1 and as-aos 2 plants restored the activity of TrypPIs and the resistance to SSB (Figure 4c,d). Fourth, silencing OsAOS1 or OsAOS2 enhanced levels of $\mathrm{BPH}$-induced $\mathrm{H}_{2} \mathrm{O}_{2}$ and the resistance of rice to $\mathrm{BPH}$ (Figure 5). These data suggest that both OsAOS1 and OsAOS2 are involved in the biosynthesis of herbivore-induced JA 
and that the JA signaling pathway plays a key role in regulating the resistance of rice to SSB and BPH directly or indirectly via modulating other signaling pathways.

Consistent with previous reports in many plant species, such as Arabidopsis, that the expression of $A O S$ is rapidly induced by herbivore infestation or mechanical wounding $[13,30]$, we found that both OsAOS1 and OsAOS2 were induced by mechanical wounding, herbivore (SSB or BPH) infestation, and JA treatment (Figure 1). Exogenous application of SA has been reported to affect $A O S$ transcript levels differently in different plant species. In barley, for example, SA treatment did not influence the expression of either AOS1 or AOS2 [14], whereas in Arabidopsis, SA treatment upregulated the transcript level of $A O S$ [31]. In this study, we observed that the exogenous application of SA had no effect on transcript levels of either OsAOS1 or OsAOS2 within $24 \mathrm{~h}$ (Figure S3). This finding was consistent with the result reported in Agrawal et al. [18], who found that SA-induced OsAOS2 expression was detectable only at $48 \mathrm{~h}$ or more after treatment.

Mei et al. [26] reported that the overexpression of OsAOS2 increases the JA level in rice. Here, we observed that silencing OsAOS1 or OsAOS2 decreased levels of SSBor BPH-induced JA (Figure $2 \mathrm{a}-\mathrm{c}$ ). These findings demonstrate that, consistent with results reported in other plant species [32], both rice AOS genes, OsAOS1 and OsAOS2, are essential in the production of JA. Intriguingly, silencing OsAOS1 decreased not only constitutive levels of JA but also levels of SSB-induced JA 1.5 and $3 \mathrm{~h}$ after SSB infestation, whereas silencing OsAOS2 reduced levels of SSB-induced JA only $3 \mathrm{~h}$ after SSB infestation (Figure 2a,b); moreover, silencing OsAOS1 or OsAOS2 had a similar effect on gravid BPH female-induced levels of JA (Figure 2c). This different effect of OsAOS1 and OsAOS2 on herbivore-induced JA biosynthesis well-matched their expression patterns: OsAOS1 responded to SSB infestation and JA treatment more quickly than did OsAOS2, whereas both genes were similarly responsive to $\mathrm{BPH}$ infestation (Figure 1). These results indicate that OsAOs1 and OsAOS2 play an important but slightly different role in the biosynthesis of herbivore-induced JA.

In addition to JA, we also found that silencing OsAOS1 or OsAOS2 increased levels of SSB- or BPH-induced SA (Figure 2d-f) and of BPH-induced $\mathrm{H}_{2} \mathrm{O}_{2}$ (Figure 5e). Antagonistic crosstalk between JA and SA has been well documented in many plant species, including rice $[33,34]$. Moreover, in rice, it has been reported that impaired JA biosynthesis enhances the level of BPH-induced $\mathrm{H}_{2} \mathrm{O}_{2}[25,28]$. Hence, the increase in levels of SSB- or BPHinduced SA and of $\mathrm{BPH}$-elicited $\mathrm{H}_{2} \mathrm{O}_{2}$ in as-aos1 and as-aos2 lines is probably due to the decrease in levels of herbivore-induced JA in these plants.

In rice, the JA signaling pathway has been reported to positively modulate the biosynthesis of many defensive compounds, such as TrypPIs and volatiles, and the resistance of rice to herbivores $[25,34]$. Moreover, TrypPIs and herbivore-induced plant volatiles are important direct and indirect defensive compounds in the resistance of rice to SSB $[25,27,28,34]$. Therefore, the decrease in levels of SSB-induced TrypPIs and volatiles in as-aos1 and as-aos2 lines, compared to WT plants, occurs mainly because levels of SSB-elicited JA in these lines are low. Moreover, the attenuated SSB resistance in as-aos1 and as-aos2 plants, compared to in WT plants, is probably due to their relatively lower TrypPI activity. The fact that supplementation with JA restores the activity of induced TrypPIs and the resistance to SSB in as-aos1 and as-aos2 lines also supports these inferred conclusions stated above. Whether changed SSB-induced rice volatiles also directly influence the performance of SSB and thereby influence the resistance of rice remains to be elucidated.

Unlike the result that silencing OsAOS1 or OsAOS2 decreased the resistance of rice to SSB caterpillars, silencing OsAOS1 or OsAOS2 enhanced the resistance of rice to BPH (Figure 5a-d). These results confirmed our previous results showing that plants with JA pathways impaired by silencing a LOX gene, OsHI-LOX, were more resistant to $\mathrm{BPH}$ than WT plants [25]. Both SA [35] and $\mathrm{H}_{2} \mathrm{O}_{2}$ [25,29] pathways positively modulate the resistance of rice to $\mathrm{BPH}$. Hence, the increase in resistance to $\mathrm{BPH}$ in as-aos1 and as-aos 2 lines might be related to higher levels of herbivore-induced SA and $\mathrm{H}_{2} \mathrm{O}_{2}$ in these lines compared to WT plants. 
In summary, our results demonstrate that the two rice AOS genes, OsAOS1 and OsAOS2, are involved in the biosynthesis of wounding- and herbivore-induced JA, a process that in turn plays an important role in mediating the resistance of rice to chewing and phloem-feeding herbivores directly or indirectly by modulating other signaling pathways.

\section{Materials and Methods}

\subsection{Plants and Insects}

In this study, the rice genotypes used were Xiushui 11 (WT) and transgenic lines as-aos1 and as-aos 2 (see details below). Pre-germinated seeds of all the lines were cultured in plastic bottles (height $10 \mathrm{~cm}$, diameter $8 \mathrm{~cm}$ ) in the greenhouse $\left(27 \pm 1^{\circ} \mathrm{C}, 14-\mathrm{L}: 10-\mathrm{D}\right)$. One-week-old seedlings were transferred to $20 \mathrm{~L}$ hydroponic boxes with a rice nutrient solution [36]. After 30-35 days, seedlings were transplanted to individual plastic pots containing $500 \mathrm{~mL}$ hydroponic nutrient solution. Plants were used for experiments $4-5$ days after transplantation. Colonies of BPH and SSB were originally collected from rice fields in Hangzhou, China, and maintained on rice seedlings of Xianyou 63, a variety susceptible to BPH and SSB, in a controlled climate room at $27 \pm 1{ }^{\circ} \mathrm{C}, 12$-h light phase, and $80 \%$ relative humidity.

\subsection{Cloning and Sequence Analysis of OsAOS1 and OsAOS2}

The full-length cDNAs of OsAOS1 and OsAOS2 were amplified by PCR. The primers (Table S2) were designed based on the sequence of two rice AOS genes (TIGR ID Os03g55800 and Os03g12500). The PCR products were gel purified, cloned into the PMD19-T vector (TaKaRa, Kusatsu, Japan), and sequenced. DNA sequences were obtained using Basic Local Alignment Search Tool (BLAST) searches (https://blast.ncbi.nlm.nih.gov/ accessed on 5 November 2020). Amino acid sequences were deduced and analyzed using DNAMAN (https: / / www.lynnon.com/ accessed on 5 November 2020).

\subsection{Quantitative Real-Time PCR}

Total RNA was isolated using SV Total RNA Isolation System (Promega, Madison, WI, USA) following the manufacturer's instructions. cDNA was synthesized from $1 \mu \mathrm{g}$ of each total RNA sample, using the Prime-Script ${ }^{\mathrm{TM}}$ RT-PCR Kit (TaKaRa, Kusatsu, Japan). The qRT-PCR assay was performed on the ABI PRISM sequence detection system (Applied Biosystem, Foster City, CA, USA) using a Premix EX Taq ${ }^{\mathrm{TM}}$ Kit (TaKaRa, Kusatsu, Japan). The expression level of target gene was normalized to the rice actin gene OsACT (TIGR ID Os03g50885). The primers and probes used for qRT-PCR analysis in this study are provided in Table S2. Five independent biological replicates were carried out.

\subsection{Generation and Characterization of as-aos Transgenic Lines}

A 728-bp (1072-1799) fragment of OsAOS1 and a 447-bp (1396-1842) fragment of OsAOS2 were cloned and inserted into the pCAMBIA-1301 transformation vector individually to obtain two antisense constructs. Both vectors were inserted into the Xiushui 11 plants via Agrobacterium tumefaciens-mediated transformation. Rice transformation, screening of the homozygous $\mathrm{T}_{2}$ plants, and identification of the number of insertions were performed following the same method as described previously [25]. Three $\mathrm{T}_{2}$ homozygous lines of as-aos1 (as1-3, as1-5, and as1-10) and three lines of as-aos2 (as2-10, as2-20, and as2-58), each with single insert, were used in subsequent experiments.

\subsection{Plant Treatments}

For SSB treatment, individual plant bases were infested with a third-instar larva of SSB that had been starved for $2 \mathrm{~h}$ before the experiment. Control plants were not manipulated (Con). For BPH treatment, individual plant bases were confined in the glass cylinders (diameter $4 \mathrm{~cm}$, height $8 \mathrm{~cm}$, with 48 small holes, diameter $0.8 \mathrm{~mm}$; Figure 59 ) into which 13 gravid BPH females were released. Plants confined to empty cylinders were used as controls (Non-infested). Mechanically wounded plants were individually pricked 200 times 
with a needle on the low side of their leaf sheaths (W). Non-manipulated plants were used as controls (Con). For JA and SA treatments, plants were individually sprayed with $2 \mathrm{~mL}$ of JA $\left(100 \mu \mathrm{g} \mathrm{mL}^{-1}\right)$ or SA $\left(70 \mu \mathrm{g} \mathrm{mL}^{-1}\right)$ solution in $50 \mathrm{mM}$ sodium phosphate buffer using the same method as described previously [25]. Control plants were sprayed with $2 \mathrm{~mL}$ of the buffer (BUF).

\section{6. $J A, S A$ and $\mathrm{H}_{2} \mathrm{O}_{2}$ Analysis}

WT, as-aos1, and as-aos2 plants were randomly assigned to control, SSB, and BPH treatments. For JA and SA analysis, rice leaf sheaths were harvested at $0,1.5$, and $3 \mathrm{~h}$, and at $0,3,8,24$, and $48 \mathrm{~h}$ after infestation with SSB and BPH, respectively. JA and SA were extracted with ethyl acetate spiked with labeled internal standards and analyzed by the high performance liquid chromatography combined with tandem mass spectrometry (HPLC/MS/MS) system, as described previously [37]. Each treatment at each time interval was replicated five times.

For $\mathrm{H}_{2} \mathrm{O}_{2}$ analysis, leaf sheaths were harvested at 0,8 , and $24 \mathrm{~h}$ after gravid $\mathrm{BPH}$ female infestation. $\mathrm{H}_{2} \mathrm{O}_{2}$ concentrations were determined as described [38]. Each treatment at each time interval was replicated five times.

\subsection{Analysis of TrypPI Activity}

WT, as-aos1, and as-aos2 plants were randomly assigned to SSB and JA+SSB treatment. For JA + SSB treatment, the plants were treated with JA for 1 day as stated above, then infested by a third-instar SSB larvae. Leaf sheaths $(0.12-0.15 \mathrm{~g})$ of each plant were harvested 3 days after the start of SSB infestation. TrypPI levels were measured using a radial diffusion assay as described in van Dam et al. [39]. Each treatment at each time interval was replicated five times.

\subsection{Collection, Isolation and Identification of Rice Volatiles}

Volatiles emitted were collected from individual plants (one plant per pot) of each line that was infested with SSB for $24 \mathrm{~h}$ or non-manipulated plants. The compounds were expressed as percentages of peak areas relative to the internal standard (IS, diethyl sebacate) per $8 \mathrm{~h}$ of trapping one plant. The collection, isolation, and identification of rice volatile were carried out as described in Lou et al. [40]. Collections were replicated five times for each treatment.

\subsection{Herbivore Bioassays}

Three freshly hatched SSB larvae were allowed to feed on each WT, as-aos1, and as-aos2 plant or on each WT, as-aos1, and as-aos 2 plant that was treated for 1 day with JA, as stated above. Larval mass (to an accuracy of $0.1 \mathrm{mg}$ ) was measured 12 days after the start of the experiment. Thirty plants were used for each line or treatment. To explore the difference in the tolerance of WT, as-aos1, and as-aos2 lines to SSB attack, plants of WT, as-aos1, and as-aos2 lines were individually infested with one third-instar SSB larva. The damage levels of plants were checked, and photographs were taken daily.

To determine the colonization and oviposition behavior of BPH females, pots with two plants (a transgenic and a WT plant) were individually confined in glass cylinders. Each cylinder received 13 gravid $\mathrm{BPH}$. The number of BPH on each plant was counted at 1 , $2,4,8,24$, and $48 \mathrm{~h}$ after their release, and $48 \mathrm{~h}$ later, the insects were removed and the eggs on each plant counted under a microscope. The experiments were replicated ten times. The survival rates of $\mathrm{BPH}$ nymphs on WT and transgenic plants were also investigated. Plants were individually confined with the glass cylinders, into which $10 \mathrm{BPH}$ neonates were introduced. The numbers of surviving insects on each plant were recorded each day until 12 days after the release of the herbivore. Ten independent replications were performed. 


\subsection{Data Analysis}

The differences in expression levels of genes after various treatments, and the colonization and oviposition behavior of $\mathrm{BPH}$ on various lines were analyzed using Student's $t$-test. The differences in JA, SA, $\mathrm{H}_{2} \mathrm{O}_{2}$, TrypPI and volatiles levels, SSB mass, and $\mathrm{BPH}$ survival rate were compared using one-way analysis of variance (ANOVA) followed by Tukey's honest significant difference (HSD) post-hoc test. Data were analyzed with Statistica (Statistica, SAS Institute Inc., Cary, NC, USA).

Supplementary Materials: The following are available online at https:/ /www.mdpi.com/2223-7 747/10/3/442/s1. Table S1. Volatile compounds emitted from non-manipulated and SSB-infested plants (24 h) of as-aos1, as-aos2, and wild-type lines. Table S2. Primers and probes used in this study. Figure S1. The nucleotide and deduced amino acid sequence of OsAOS1 and OsAOS2. Figure S2. Alignment of the nucleotide and amino acid sequence of OsAOS1 and OsAOS2. Figure S3. Expression levels of OsAOS1 and OsAOS2 in rice plants that were treated with SA. Figure S4. The transformation vector used to generate the as-aos1 and as-aos2 lines. Figure S5. DNA gel-blot analysis of as-aos1 and as-aos2 plants. Figure S6. Expression levels of OsAOS1 and OsAOS2 in rice plants that were infested by SSB. Figure S7. Expression levels of OsAOS1 and OsAOS2 in as-aos1, as-aos2, and WT plants that were infested by SSB. Figure S8. Growth phenotypes of as-aos1, as-aos2, and WT plants at one-week-old seedling stage, tillering stage, and heading stage. Figure S9. The setup used for herbivore bioassays.

Author Contributions: Y.L. conceived the study. J.Z., T.Z., J.H., and R.L. designed and performed the experiments, analyzed the data. J.Z. and T.Z. wrote the manuscript. Y.L. edited and reviewed the manuscript. All authors have read and agreed to the published version of the manuscript.

Funding: The study was jointly sponsored by the National Natural Science Foundation of China (31930091) and the earmarked fund for China Agriculture Research System (CARS-01-40).

Institutional Review Board Statement: Not applicable.

Informed Consent Statement: Not applicable.

Data Availability Statement: The data presented in this study are available on request from the corresponding author.

Acknowledgments: We thank Emily Wheeler for editorial assistance.

Conflicts of Interest: The authors declare no conflict of interest.

\section{References}

1. Wu, J.; Baldwin, I.T. New insights into plant responses to the attack from insect herbivores. Annu. Rev. Genet. 2010, 44, 1-24. [CrossRef]

2. War, A.R.; Paulraj, M.G.; Ahmad, T.; Buhroo, A.A.; Hussain, B.; Ignacimuthu, S.; Sharma, H.C. Mechanisms of plant defense against insect herbivores. Plant Signal. Behav. 2012, 7, 1306-1320. [CrossRef]

3. Chung, H.S.; Koo, A.J.K.; Gao, X.; Jayanty, S.; Thines, B.; Jones, A.D.; Howe, G.A. Regulation and Function of Arabidopsis JASMONATE ZIM-Domain Genes in Response to Wounding and Herbivory. Plant Physiol. 2008, 146, 952-964. [CrossRef]

4. Erb, M.; Meldau, S.; Howe, G.A. Role of phytohormones in insect-specific plant reactions. Trends Plant Sci. 2012, 17, 250-259. [CrossRef] [PubMed]

5. Schuman, M.C.; Baldwin, I.T. The Layers of Plant Responses to Insect Herbivores. Annu. Rev. Entomol. 2016, 61, 373-394. [CrossRef] [PubMed]

6. Lyons, R.; Manners, J.M.; Kazan, K. Jasmonate biosynthesis and signaling in monocots: A comparative overview. Plant Cell Rep. 2013, 32, 815-827. [CrossRef]

7. Liu, Z.; Zhang, S.; Sun, N.; Liu, H.; Zhao, Y.; Liang, Y.; Zhang, L.; Han, Y. Functional diversity of jasmonates in rice. Rice 2015, 8, 5. [CrossRef]

8. Schaller, A.; Stintzi, A. Enzymes in jasmonate biosynthesis-Structure, function, regulation. Phytochemistry 2009, 70, 1532-1538. [CrossRef]

9. Farmer, E.E.; Goossens, A. Jasmonates: What ALLENE OXIDE SYNTHASE does for plants. J. Exp. Biol. 2019, 70, 3373-3378. [CrossRef]

10. Wasternack, C.; Feussner, I. The Oxylipin Pathways: Biochemistry and Function. Annu. Rev. Plant Biol. 2018, 69, 363-386. [CrossRef] 
11. Chehab, E.W.; Perea, J.V.; Gopalan, B.; Theg, S.; Dehesh, K. Oxylipin Pathway in Rice and Arabidopsis. J. Integr. Plant Biol. 2007, 49, 43-51. [CrossRef]

12. Mosblech, A.; Feussner, I.; Heilmann, I. Oxylipins: Structurally diverse metabolites from fatty acid oxidation. Plant Physiol. Biochem. 2009, 47, 511-517. [CrossRef]

13. Laudert, D.; Pfannschmidt, U.; Lottspeich, F.; Holländer-Czytko, H.; Weiler, E.W. Cloning, molecular and functional characterization of Arabidopsis thaliana allene oxide synthase (CYP 74), the first enzyme of the octadecanoid pathway to jasmonates. Plant Mol. Biol. 1996, 31, 323-335. [CrossRef]

14. Maucher, H.; Hause, B.; Feussner, I.; Ziegler, J.; Wasternack, C. Allene oxide synthases of barley (Hordeum vulgare cv. Salome): Tissue specific regulation in seedling development. Plant J. 2000, 21, 199-213. [CrossRef]

15. Howe, G.A.; Lee, G.I.; Itoh, A.; Li, L.; DeRocher, A.E. Cytochrome P450-Dependent Metabolism of Oxylipins in Tomato. Cloning and Expression of Allene Oxide Synthase and Fatty Acid Hydroperoxide Lyase1. Plant Physiol. 2000, 123, 711-724. [CrossRef]

16. Sivasankar, S.; Sheldrick, B.; Rothstein, S.J. Expression of Allene Oxide Synthase Determines Defense Gene Activation in Tomato1. Plant Physiol. 2000, 122, 1335-1342. [CrossRef]

17. Stumpe, M.; Göbel, C.; Demchenko, K.; Hoffmann, M.; Klösgen, R.B.; Pawlowski, K.; Feussner, I. Identification of an allene oxide synthase (CYP74C) that leads to formation of $\alpha$-ketols from 9-hydroperoxides of linoleic and linolenic acid in below-ground organs of potato. Plant J. 2006, 47, 883-896. [CrossRef]

18. Agrawal, G.K.; Rakwal, R.; Jwa, N.; Han, K.; Agrawal, V.P. Molecular cloning and mRNA expression analysis of the first rice jasmonate biosynthetic pathway gene allene oxide synthase. Plant Physiol. Biochem. 2002, 40, 771-782. [CrossRef]

19. Ha, S.B.; Lee, B.C.; Lee, D.E.; Kuk, Y.I.; Lee, A.Y.; Han, O.; Back, K. Molecular characterization of the gene encoding rice allene oxide synthase and its expression. Biosci. Biotechnol. Biochem. 2002, 66, 2719-2722. [CrossRef]

20. Haga, K.; Iino, M. Phytochrome-mediated transcriptional up-regulation of ALLENE OXIDE SYNTHASE in rice seedlings. Plant Cell Physiol. 2004, 45, 119-128. [CrossRef] [PubMed]

21. Agrawal, G.K.; Tamogami, S.; Han, O.; Iwahashi, H.; Rakwal, R. Rice octadecanoid pathway. Biochem. Biophys. Res. Commun. 2004, 317, 1-15. [CrossRef] [PubMed]

22. Lou, Y.; Zhang, G.; Zhang, W.; Hu, Y.; Zhang, J. Biological control of rice insect pests in China. Biol. Control 2013, 67, 8-20. [CrossRef]

23. Chen, M.; Shelton, A.; Ye, G.Y. Insect-resistant genetically modified rice in China: From research to commercialization. Annu. Rev. Entomol. 2011, 56, 81-101. [CrossRef]

24. Lu, J.; Li, J.; Ju, H.; Liu, X.; Erb, M.; Wang, X.; Lou, Y. Contrasting Effects of Ethylene Biosynthesis on Induced Plant Resistance against a Chewing and a Piercing-Sucking Herbivore in Rice. Mol. Plant 2014, 7, 1670-1682. [CrossRef] [PubMed]

25. Zhou, G.; Qi, J.; Ren, N.; Cheng, J.; Erb, M.; Mao, B.; Lou, Y. Silencing OsHI-LOX makes rice more susceptible to chewing herbivores, but enhances resistance to a phloem feeder. Plant J. 2009, 60, 638-648. [CrossRef] [PubMed]

26. Mei, C.; Qi, M.; Sheng, G.; Yang, Y. Inducible overexpression of a rice allene oxide synthase gene increases the endogenous jasmonic acid level, PR gene expression, and host resistance to fungal infection. Mol. Plant-Microbe Interact. 2006, 19, 1127-1137. [CrossRef]

27. Qi, J.; Zhou, G.; Yang, L.; Erb, M.; Lu, Y.; Sun, X.; Cheng, J.; Lou, Y. The Chloroplast-Localized Phospholipases D $\alpha 4$ and $\alpha 5$ Regulate Herbivore-Induced Direct and Indirect Defenses in Rice. Plant Physiol. 2011, 157, 1987-1999. [CrossRef] [PubMed]

28. Lu, J.; Ju, H.; Zhou, G.; Zhu, C.; Erb, M.; Wang, X.; Wang, P.; Lou, Y. An EAR-motif-containing ERF transcription factor affects herbivore-induced signaling, defense and resistance in rice. Plant J. 2011, 68, 583-596. [CrossRef]

29. Hu, L.; Ye, M.; Li, R.; Lou, Y. OsWRKY53, a versatile switch in regulating herbivore-induced defense responses in rice. Plant Signal. Behav. 2016, 11, e1169357. [CrossRef] [PubMed]

30. Van Poecke, R.M.; Posthumus, M.A.; Dicke, M. Herbivore-induced volatile production by Arabidopsis thaliana leads to attraction of the parasitoid Cotesia rubecula: Chemical, behavioral, and gene-expression analysis. J. Chem. Ecol. 2001, 27, 1911-1928. [CrossRef]

31. Laudert, D.; Weiler, E.W. Allene oxide synthase: A major control point in Arabidopsis thaliana octadecanoid signalling. Plant J. 1998, 15, 675-684. [CrossRef] [PubMed]

32. Ziegler, J.; Keinänen, M.; Baldwin, I.T. Herbivore-induced allene oxide synthase transcripts and jasmonic acid in Nicotiana attenuata. Phytochemistry 2001, 58, 729-738. [CrossRef]

33. Lee, A.; Cho, K.; Jang, S.; Rakwal, R.; Iwahashi, H.; Agrawal, G.K.; Shim, J.; Han, O. Inverse correlation between jasmonic acid and salicylic acid during early wound response in rice. Biochem. Biophys. Res. Commun. 2004, 318, 734-738. [CrossRef] [PubMed]

34. Hu, L.; Ye, M.; Kuai, P.; Ye, M.; Erb, M.; Lou, Y. OsLRR-RLK1, an early responsive leucine-rich repeat receptor-like kinase, initiates rice defense responses against a chewing herbivore. New Phytol. 2018, 219, 1097-1111. [CrossRef]

35. Du, B.; Zhang, W.; Liu, B.; Hu, J.; Wei, Z.; Shi, Z.; He, R.; Zhu, L.; Chen, R.; Han, B.; et al. Identification and characterization of Bph14, a gene conferring resistance to brown planthopper in rice. Proc. Natl. Acad. Sci. USA 2009, 106, 22163-22168. [CrossRef] [PubMed]

36. Yoshida, S.; Forno, D.A.; Cock, J.H.; Gomez, K.A. Laboratory Manual for Physiological Studies of Rice, 3rd ed.; International Rice Research Institute: Los Baños, PH, USA, 1976.

37. Lu, J.; Robert, C.A.M.; Riemann, M.; Cosme, M.; Mène-Saffrané, L.; Massana, J.; Stout, M.J.; Lou, Y.; Gershenzon, J.; Erb, M. Induced Jasmonate Signaling Leads to Contrasting Effects on Root Damage and Herbivore Performance. Plant Physiol. 2015, 167, 1100-1116. [CrossRef] [PubMed] 
38. Lou, Y.; Baldwin, I.T. Silencing of a Germin-Like Gene in Nicotiana attenuata Improves Performance of Native Herbivores. Plant Physiol. 2006, 140, 1126-1136. [CrossRef] [PubMed]

39. van Dam, N.M.; Horn, M.; Mares, M.; Baldwin, I.T. Ontogeny constrains systemic protease inhibitor response in Nicotiana attenuata. J. Chem. Ecol. 2001, 27, 547-568. [CrossRef] [PubMed]

40. Lou, Y.; Du, M.; Turlings, T.C.J.; Cheng, J.; Shan, W. Exogenous application of jasmonic acid induces volatile emissions in rice and enhances parasitism of Nilaparvata lugens eggs by the parasitoid Anagrus nilaparvatae. J. Chem. Ecol. 2005, 31, 1985-2002. [CrossRef] [PubMed] 